\title{
NOTE ON SOME FORMULAS OF RODEJA F.
}

L. CARLITZ

Generalizing some identities proved by A. W. Goodman [1], Rodeja F. [3] proved the formula

$$
\sum_{m=k}^{n} \frac{G_{n} \prod_{\alpha=1}^{m-1}\left(F_{n}-F_{\alpha}\right)}{G_{k} \prod_{\alpha=1}^{k-1}\left(F_{k}-F_{\alpha}\right) \prod_{\alpha=k+1}^{m}\left(F_{k}-F_{\alpha}\right)}=\delta_{n}^{k} \quad(n \geqq k \geqq 1),
$$

where as usual a vacuous product is defined equal to 1 ; it is remarked that the factor $G_{n} / G_{k}$ may be omitted without any loss in generality. It is easily verified that (1) is equivalent to

$$
\sum_{m=k}^{n} \prod_{\alpha=1}^{m-1}\left(F_{n}-F_{\alpha}\right) \prod_{\alpha=m+1}^{n}\left(F_{k}-F_{\alpha}\right)=\delta_{k}^{n} \prod_{\alpha=1, \alpha \neq k}^{n}\left(F_{k}-F_{\alpha}\right) .
$$

The author also states the somewhat more general formula

(3) $\sum_{m=k}^{\infty} \prod_{\alpha=k}^{m-1}\left(F_{n}-F_{\alpha}\right) \prod_{\alpha=m+1}^{n}\left(F_{k}-F_{\alpha}\right)=\prod_{\alpha=k+1}^{s}\left(F_{n}-F_{\alpha}\right) \prod_{\alpha=\sigma+1}^{n}\left(F_{k}-F_{\alpha}\right)$,

which reduces to (2) for $s=n$. Clearly in (3) we may assume $k=1$, $n \geqq s$ without any loss in generality.

We wish to point out in this note that the formula (3) is a special case of the Newton interpolation formula (see for example [2, p. 10]). If $f(x)$ is a polynomial of degree less than $s$, then in the notation of [2],

$$
\begin{aligned}
f(x)= & f\left(x_{1}\right)+\left[x_{1} x_{2}\right]\left(x-x_{1}\right)+\left[x_{1} x_{2} x_{3}\right]\left(x-x_{1}\right)\left(x-x_{2}\right)+\cdots \\
& +\left[x_{1} x_{2} \cdots x_{8}\right]\left(x-x_{1}\right)\left(x-x_{2}\right) \cdots\left(x-x_{8-1}\right)
\end{aligned}
$$

where

$$
\left[x_{1} x_{2}\right]=\frac{f\left(x_{1}\right)-f\left(x_{2}\right)}{x_{1}-x_{2}},\left[x_{1} x_{2} x_{3}\right]=\frac{\left[x_{1} x_{2}\right]-\left[x_{2} x_{3}\right]}{x_{1}-x_{3}}, \ldots .
$$

In particular if we take

$$
f(x)=\left(x-x_{2}\right)\left(x-x_{3}\right) \cdots\left(x-x_{8}\right),
$$

then it is easy to verify that

Received by the editors September 5, 1953. 
(5)

$$
\left[x_{1} x_{2} \cdots x_{r}\right]=\left(x_{1}-x_{r+1}\right) \cdots\left(x_{1}-x_{s}\right) \quad(2 \leqq r \leqq s) .
$$

Substituting from (5), it is evident that (4) becomes

$$
\prod_{\alpha=2}^{\dot{s}}\left(x-x_{\alpha}\right)=\sum_{m=1} \dot{\prod}_{\alpha=m+1}\left(x_{1}-x_{\alpha}\right) \prod_{\alpha=1}^{m-1}\left(x-x_{\alpha}\right) \text {. }
$$

If we put $x=F_{n}, x_{\alpha}=F_{\alpha}$, (6) becomes

$$
\prod_{\alpha=2}^{\dot{s}}\left(F_{n}-F_{\alpha}\right)=\sum_{m=1}^{\dot{s}} \prod_{\alpha=m+1}^{s}\left(F_{1}-F_{\alpha}\right) \prod_{\alpha=1}^{m-1}\left(F_{n}-F_{\alpha}\right),
$$

which proves (3).

\section{REFERENCES}

1. A. W. Goodman, On some determinants related to p-ralent functions, Trans. Amer. Math. Soc. vol. 63 (1948) pp. 175-192.

2. N. E. Nörlund, Vorlesungen ïber differenzenrechnung, Berlin, 1924.

3. E. G. Rodeja F., Note on a lemma of A. W. Goodman, Proc. Amer. Math. Soc. vol. 2 (1951) pp. 314-317.

DUKe UnIVERSITY 